\title{
Study on residual oil recovery from empty fruit bunch by combination of water and steam process
}

\begin{abstract}
In this study, the recovery of residual oil from the spikelet of oil palm empty fruit bunches (OPEFB) was conducted. Residual oil was present in the OPEFB due to mechanical processes such as the loading of fruit into the sterilizer cage, sterilization and threshing, in which a certain portion of the oil from the fruitlet was impregnated mainly on the surface of the spikelet rather than on the stalk of OPEFB. The highest residual oil content was found mainly in the small OPEFB (28.49田的 $20 \%$ dry basis). The oil extraction process was introduced as hydro solvent-assisted steam extraction, which comprises of four main steps, i.e., flooding, injection, soaking and draining. The overall process resulted in above $83 \%$ residual oil removal from the spikelet. The proposed method can be an option to be implemented in the palm oil mill because it is a chemical-free, environment-friendly and novel process.
\end{abstract}

Keyword: Residual oil recovery; Empty fruit bunch; Water; Steam process 